\title{
IMPLANTAÇÃO DA ESCOLA MUNICIPAL DE ENSINO FUNDAMENTAL FILHO DO MINEIRO
}

\section{IMPLANTATION OF BASIC SCHOOL FILHO DO MINEIRO (CRICIÚMA - SC)}

\author{
Bibiana Trindade de Freitas ${ }^{1}$ \\ Giani Rabelo ${ }^{2}$
}

\section{RESUMO}

$\mathrm{O}$ artigo aqui apresentado procura dar visibilidade à implantação da EMEF Filho do Mineiro na década de 1970, este que reconta parte se sua trajetória com o intuito de contribuir para a história e memória das instituições escolares de Criciúma. O objetivo principal desta pesquisa foi analisar como se deu a implantação da EMEF Filho do Mineiro, tendo como principal questão a origem do nome atribuído à escola e as características sociais e econômicas da comunidade do Distrito de Rio Maina no momento de sua implantação, entre outros. Como metodologia utilizou-se da abordagem qualitativa com o uso de fontes documentais e orais.

Através deste trabalho pude compreender a relação existente entre a Carbonífera Metropolitana e a Vila Operária de mesmo nome, esta relação que foi o alicerce de sustentação para que a localidade expandisse e deixasse de ser somente mais uma pequena Vila de Operários. Diante disso, se pode entender a importância da implantação da EMEF Filho do Mineiro para a comunidade do Bairro Metropol. Os objetivos propostos nesta pesquisa foram alcançados com base nos poucos documentos encontrados e nas memórias dos entrevistados. Contudo, é lamentável saber que muitos documentos e registros fundamentais para a história desta instituição de ensino tenham se perdido ao longo do tempo. De qualquer forma, acredito que esta pesquisa contribuirá para a preservação de parte deste patrimônio educativo que foi e é tão importante para as famílias que moraram no referido bairro e que ainda moram.

PALAVRAS CHAVE: Educação. Carvão. Memória.

\section{ABSTRACT ABSTRACT}

The article here presented seeks to give visibility to the implementation of the Town Public School Miner's Son (EMEF Filho do Mineiro) in the 1970s, recounting this part if its trajectory in order to contribute to the history and memory of educational institutions of Criciuma. The main objective of this research was to analyze how was the implementation of Town Public

\footnotetext{
${ }^{1}$ Acadêmica do curso de Pedagogia, bibianatrindade@bol.com.br

${ }^{2}$ Doutora em Educação. PPGE/UNESC, gra@unesc.net 
School Miner's Son, the main question the origin of the name assigned to the school and the social and economic characteristics of the Maina River District community at the time of its implementation, among others. The methodology we used a qualitative approach with the use of documentary and oral sources.

Through this work I was able to understand the relationship between the Metropolitan Carboniferous and the Workers' Village of the same name, this relationship was the foundation supports for the towns expands and stop being just another small village of Workers. Therefore, one can understand the importance of implementation of the Town Public School Miner's Son to the community of Metropol neighborhood. The objectives proposed in this study were achieved based on the few documents found and in the memories of respondents. However, it is unfortunate to know that many documents and basic records for the history of this educational institution have been lost over time. Anyway, I believe that this research will contribute to the preservation of this educational heritage that was and is so important for families who lived in that neighborhood and still live.

KEYWORDS: Education. Coal. Memory.

\section{INTRODUÇÃO}

O artigo aqui apresentado objetiva analisar a implantação da Escola Municipal de Ensino Fundamental Filho do Mineiro no bairro Metropol, localizado no Distrito de Rio Maina/Criciúma (SC). Há indícios de que a escola surgiu na década de 1970, no entanto, não foi possível encontrar no acervo da escola os documentos oficiais do período de implantação do educandário. Por isso foi necessário contar com as lembranças de duas ex-alunas e um exaluno que estudaram na referida escola no início da década de 1970.

O surgimento deste tema deu-se a partir do momento em que vim morar no Distrito do Rio Maina no ano de 2010 quando tive necessidade de encontrar uma escola de Ensino Fundamental para minhas filhas que na época tinham 9 anos de idades e estavam prestes a iniciar o $3^{\circ}$ ano das séries iniciais. Como minha preferência era por escola da Rede Municipal de Ensino, deparei-me com este educandário.

A princípio o que me chamou a atenção foi o nome atribuído à instituição, ou seja, EMEF Filho do Mineiro, pois o que dava a entender era que o estabelecimento destinava-se somente aos filhos dos mineiros de nossa região. Ao chegar à secretaria da escola e questionar a diretora sobre o público alvo, fui informada que a mesma era aberta a toda a comunidade do bairro Metropol e a regiões vizinhas, desde o ano de 1986.

Saberes Pedagógicos, Criciúma, v. 1, nº1, janeiro/junho 2017.- Curso de Pedagogia- UNESC 
Vale salientar que o principal objetivo desta pesquisa é analisar como se deu o processo de implantação da EMEF Filho do Mineiro no Distrito de Rio Maina/ Criciúma. Acredito, enquanto docente em formação do curso de Pedagogia da UNESC e futura pedagoga, que com este estudo eu possa contribuir para os registros da história da educação de Criciúma, assim como compreender sobre a participação das empresas mineradoras na oferta e manutenção de estabelecimentos escolares, visto que informações preliminares dão conta que a implantação da escola EMEF Filho do Mineiro contou com a participação da Empresa Carbonífera Metropolitana.

Até o presente momento não encontrei nenhum estudo que tenha esta instituição como objeto de pesquisa nos Trabalhos de Conclusão do Curso de Pedagogia da UNESC. Dos trabalhos até aqui defendidos nenhum deles se aproxima desta temática, partindo deste pressuposto, a pesquisa realizada contribui para o fortalecimento da identidade da EMEF Filho do Mineiro e sua comunidade escolar.

Junto com o principal objetivo que é analisar como se deu a implantação da EMEF Filho do Mineiro, sinto-me instigada a pesquisar sobre: Quais as razões que levaram a comunidade escolar a se definir por este nome? Qual a relação da Vila Operária com a Carbonífera Metropolitana? O que levou a Carbonífera Metropolitana a criar uma escola para os filhos e filhas de mineiros? Que estrutura foi criada para o funcionamento da escola?

Para poder responder as indagações que fundamentam esta pesquisa contei com análises documentais, depoimentos orais de pessoas que fizeram e que fazem parte da história do estabelecimento e do Bairro Metropol, além de algumas fotografias.

Este trabalho se dá no âmbito da Linha de Pesquisa Fundamentos da Educação e tem como Eixo Temático a História da Educação.

Com o intuito de compreender, identificar e analisar as questões apontadas, este estudo será de caráter exploratório descritivo, pois este terá por finalidade possibilitar ao pesquisador uma melhor familiarização com o assunto a ser pesquisado. Pois assim como afirma Pinheiro (2010, p.21), “A pesquisa exploratória visa proporcionar maior familiaridade com o problema com vista a torná-lo explícito ou a construir hipóteses. Envolvendo levantamento bibliográfico; entrevistas com pessoas que tiveram experiências práticas com o problema pesquisado".

Saberes Pedagógicos, Criciúma, v. 1, nº 1, janeiro/junho 2017.- Curso de Pedagogia- UNESC 
Através da pesquisa exploratória o indivíduo consegue se inteirar de detalhes os quais podem contribuir para o aumento de experiências e familiarização em torno de determinado assunto e com isso haverá maior compreensão e interpretação aos dados coletados, através das entrevistas, pesquisas, fotografias entre outros.

As entrevistas e coletas de dados realizaram-se com três ex-alunos da EMEF Filho do Mineiro que estudavam na escola, quando esta iniciou suas atividades no antigo hotel do bairro Metropol na década de 1970.

Para que as indagações que objetivaram esta pesquisa pudessem ser respondidas foram estabelecidos alguns diálogos com os seguintes autores: Pinheiro (2010), para definir a abordagem metodológica da pesquisa; Carola (2002), Volpato (1984), Belolli et al. (2002) para tratar do contexto regional marcado pela extração do carvão; Meihy (2005) para compreender a história oral.

O artigo está estruturado a partir dos seguintes itens: uma breve introdução, dois itens intitulados "A Carbonífera Metropolitana e a emergência da Vila Operária Metropolitana" e "A Vila Operária Metropolitana e a Escola para os filhos e filhas dos mineiros: uma escola do carvão" e a conclusão.

\section{A CARBONÍFERA METROPOLITANA E A EMERGÊNCIA DA VILA OPERÁRIA METROPOLITANA}

Não se pode falar da Vila Operária Metropolitana, hoje Bairro Metropol, localizado no Distrito de Rio Maina em Criciúma, sem antes tratarmos da trajetória da Carbonífera Metropolitana, uma das pioneiras no Complexo Carbonífero Catarinense que extrai carvão desde o início dos anos de 1940.

Atualmente fazem parte do Distrito de Rio Maina os bairros; São Marcos, Mina do Toco, Metropolitana, Laranjinha, Vila Zuleima, Cidade Mineira, Santa Luzia, Mãe Luzia e São Defende. Além desta mineradora existiram e existem outras na região, agora em menor número. Portanto, o processo de crescimento econômico da região sul de Santa Catarina não pode ser dissociado da instalação destas empresas. A instalação de mineradoras na região remonta ao final do século XIX. De acordo com Filho e Moraes (2009, p. 353-254):

Saberes Pedagógicos, Criciúma, v. 1, nº1, janeiro/junho 2017.- Curso de Pedagogia- UNESC 
[...] a primeira companhia a ser constituída foi a firma inglesa Companhia de Mineração de Carvão Tubarão, em 1883, que operou somente até 1887 e foi abandonada Somente com o advento da Primeira Guerra Mundial que efetivamente começou a ser extraído o carvão catarinense de forma mais racional, com a fundação das companhias carboníferas. Entre 1917 e 1922 foram fundadas cinco companhias: a CBCA (Companhia Brasileira Carbonífera Araranguá), a CCU (Companhia Carbonífera Urussanga S.A.), a Companhia Carbonífera Próspera S.A., a Companhia Ítalo-Brasileira Ltda. e a Companhia Nacional Mineração Barro Branco. Apenas a Cia Próspera e a Ítalo-Brasileira tinham sede em Criciúma, as demais, no Rio de Janeiro. Nos anos 1930 surgiram mais quatro companhias, nos anos 1940 mais 30, e nos 1950 mais oito, todas de pequenos proprietários locais. No final dos anos 1930 havia quatro companhias carboníferas que tinham mais de 100 trabalhadores: CCU, Barro Branco, CBCA e Rio Carvão De 1945 a 1960 surgiram na região aproximadamente 40pequenas mineradoras que atuavam de forma artesanal, todas de proprietários locais. Grande parte dessas pequenas mineradoras vendia sua produção às mineradoras de maior porte, como a CBCA, a Cia Próspera, a Barro Branco e a Carbonífera Criciúma. Com o acelerado processo de mecanização da escolha e do transporte externo, diminuiu o número de pequenas mineradoras, dando início a um processo de centralização, que resultou em doze mineradoras no início dos anos 1970.

Na década de 1980 muitas destas mineradoras fecharam pelo esgotamento das reservas de carvão, mas a Carbonífera Metropolitana se manteve e continua atuando na região.

O carvão extraído do subsolo das mineradoras do sul de Santa Catarina foram os principais responsáveis pela formação de uma categoria de trabalhadores, estes tiveram uma presença marcante no crescimento econômico do município de Criciúma e região. Para Volpato (1984, p.15):

A extração de carvão fixou na região uma categoria especial de trabalhador - o mineiro- cujo trabalho singular apresenta características que diferem das ocupações dos demais operários, seja pelas atividades de subsolo, seja pelas condições de trabalho precários e desgastantes.

A carbonífera Metropolitana S/A iniciou suas atividades de extração de carvão mineral no ano de 1936, pois antes desta data ela era uma empresa colonizadora que vendia terras aos imigrantes europeus que chegavam à região. No inicio dos anos de 1940, a Carbonífera abre sua primeira mina, a Dom Pedro, esta que se localizava no bairro Garagem entre a região de Rio Maina e Boa Vista e na época pertencia à família de Euvaldo Lodi e era representado nesta região por Artur Albino. Em 1945 a família em questão indenizou os colonos que eram donos de pequenas minas da região e as incorporou ao patrimônio da Carbonífera Metropolitana. No ano de 1948, Santos Guglielmi inicia sociedade com Diomício Freitas e, Saberes Pedagógicos, Criciúma, v. 1, nº 1, janeiro/junho 2017.- Curso de Pedagogia- UNESC 
ambos trabalham na venda de rejeito de carvão e juntos adquirem dezenas de empresas nos mais variados ramos de atividades. Em 1959, Santos Guglielmi e Diomício Freitas fecham a compra da Carbonífera Metropolitana, no Rio de Janeiro, pertencente até então ao empresário Milton Euvaldo Lodi. A sociedade entre ambos durou até o ano de 1968, quando ambos acabam dividindo as empresas. Segundo Belolli et al (2002 p.198):

\footnotetext{
A façanha empresarial de Freitas e Guglielmi, entretanto, não se limitou a esses empreendimentos. Promoveram, mais tarde, a fundação da Carbonífera Criciúma Ltda., contribuindo dessa forma para a formação de um novo grupo empresarial no setor carbonífero de Santa Catarina.
}

De acordo com as informações contidas no site da Carbonífera Metropolitana, atualmente a mesma realiza a extração de carvão na Mina Fontanella, localizada no município de Treviso (SC), com produção de cerca de 100 mil toneladas de carvão bruto ao mês, empregando cerca de 850 mineiros e técnicos. (CARBONÍFERA METROPOLITANA S/A. 2016 p. 1). A exploração do carvão em pedra na região Sul de Santa Catarina trouxe crescimento econômico para Criciúma e região, além disso, trouxe também aumento da população. Com a criação de inúmeros postos de emprego chegam à região muitas famílias, o que vai gerar a fundação de várias vilas operárias, organizadas pelas mineradoras.

Com o surgimento das inúmeras carboníferas cresce a necessidade de moradias para acomodar os operários, juntamente com suas famílias, que migram de outras cidades em busca de oportunidades e por melhores salários. Até o final da década de 1960, as casas das vilas operárias tinham um mesmo padrão, não tinham banheiros, nem água encanada, possuíam três cômodos: cozinha, sala, quarto, sendo que muitas famílias eram compostas por cinco ou mais pessoas.

Figura 01: Vila Operária da Próspera (década de 1950) 


\section{SABERES PEDAGÓGICOS}

Revista do Curso de Graduaçāo de Pedagogia - Unesc
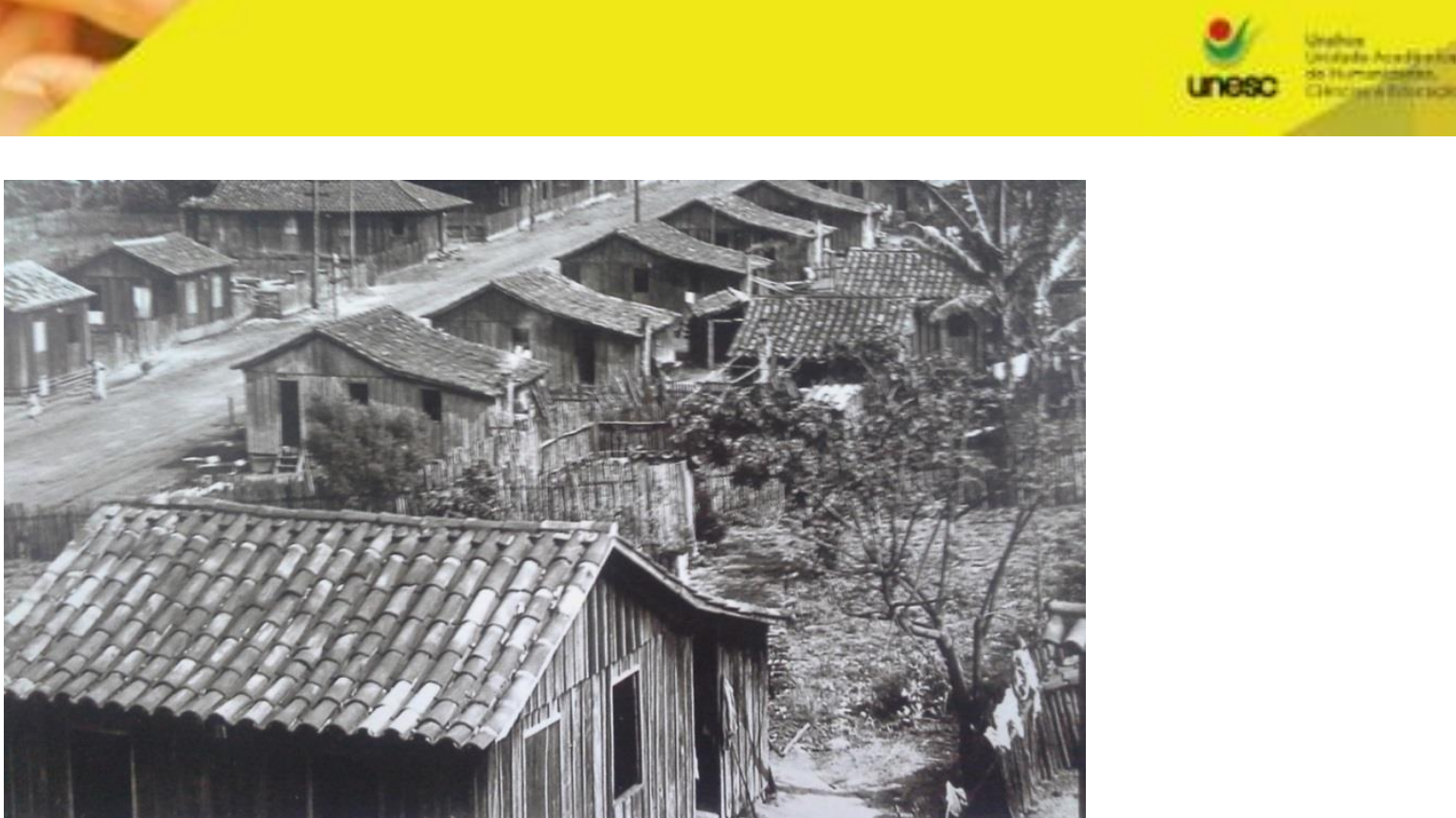

Fonte: Acervo da Biblioteca Pública de Criciúma (SC) - Jornal Tribuna Criciumense (1957)

Conforme Carola (2002, p.96), “nas principais vilas operárias, praticamente tudo pertencia aos donos das minas: os terrenos, as casas, os clubes de festas, dança, os clubes de futebol, o armazém e a escola".

Com as vantagens que as companhias carboníferas ofereciam aos seus colaboradores, elas acabavam por ter um controle total sobre suas vidas e de seus familiares, pois eles trabalhavam, divertiam-se, estudavam e faziam suas compras dentro destas vilas operárias. De certo modo isto era visto pelos operários e suas famílias como ponto positivo, pois evitava os deslocamentos a fim de atender suas necessidades básicas. Isso assegurava a permanência destes funcionários em seus respectivos empregos, além disso, os operários garantiam pra si e seu familiar emprego, moradia e a esperança de um futuro melhor para seus filhos e filhas. 
Figura 02 - Frente do gabinete dentário destinado a funcionários e familiares da Carbonífera Metropolitana.

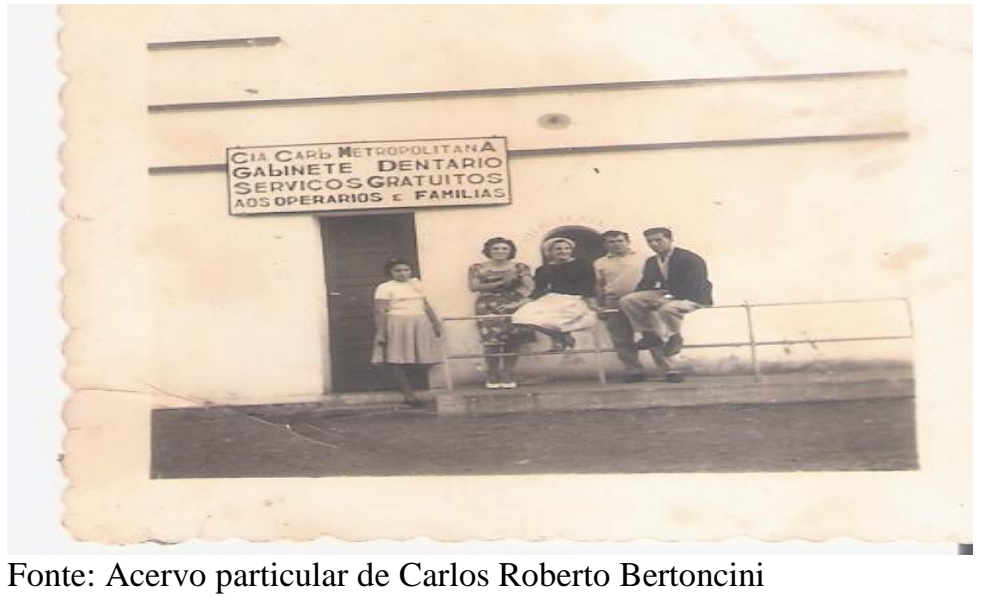

Ao discutir a condição de vida dos operários das minas de carvão de Criciúma, Volpato (1984, p.24) aponta que:

\begin{abstract}
A garantia de um nível de vida pouco acima do comum aos trabalhadores não qualificados é um dos fortes motivos que levam o trabalhador de Criciúma a se empregar nas minas. Com melhores salários, ele garante a subsistência da família e alimenta a esperança de promoção, a se concretizar nos filhos; para isto, planeja oferecer condições de "estudo" e for mação profissional a eles, para que "não necessitem trabalhar nas minas". Estes motivos, para o trabalhador mineiro, falam mais alto que a ameaça de doença, o perigo de acidentes, o desgaste físico prematuro.
\end{abstract}

Com baixa escolaridade, os operários aceitavam viver dia após dia com os riscos existentes no subsolo das minas de carvão, pois muitos deles não tinham se quer uma profissão, portanto, trabalhar nas minas era o que lhes proporcionava um salário razoável, mas este não era o futuro desejado para seus filhos. Eles acreditavam que com esta remuneração poderiam garantir uma boa formação profissional, levando seus filhos para longe dos perigos enfrentados por eles no subsolo das minas de carvão.

Entre as várias mineradoras que tinham suas sedes administrativas e minas de carvão, estavam as que se localizavam no Distrito do Rio Maina. Neste local funcionaram as seguintes mineradoras: São Marcos, Metropolitana, Catarinense e União. Cada empresa criou sua própria vila operária e a que foi criada pela Carbonífera Metropolitana recebeu a 
denominação de Metropolitana. O surgimento da Vila Operária Metropolitana deu-se nos meados dos anos de 1940. Segundo Carola (2002, p.115),

\begin{abstract}
O Bairro Metropol no auge do carvão foi um dos bairros operários de maior prestigio da 'Metrópole do carvão'. O bairro Metropol faz parte dos bairros considerados mais antigos da região de Criciúma, pois seu surgimento data a época em que o carvão era considerado uma das maiores fontes de riqueza do sul do estado. Antes de ser conhecido por bairro Metropol era chamado de Vila operária Metropolitana. Esta vila era formada em sua maior parte por operários e seus familiares, um dos critérios para terem direito a estas moradias era que fossem casados, tivessem ligação direta com a carbonífera Metropolitana e principalmente tinha que ser considerado bom funcionário. O prestígio da Vila Operária Metropolitana estava ligado ao fato de a Carbonífera Metropolitana contar com um time de futebol que surge em meio ao carvão.
\end{abstract}

A princípio o Esporte Clube Metropol foi um time de futebol fundado em 1945 com a intenção possibilitar diversão e lazer aos funcionários que trabalhavam nos subterrâneos das minas da localidade. No entanto, além deste objetivo, o time de futebol passou a ser uma forma de manter os funcionários mais passivos e obedientes aos patrões.

Por volta de 1959, quando Diomício Freitas e Santos Guglielmi se associam à Carbonífera Metropolitana, o time do Esporte Clube Metropol e seus operários acabam por sair do anonimato, ganhando visibilidade e reconhecimento na região e até fora do país. Com isso o time da sua grande arrancada para o sucesso, pois os patrões passam a conviver diretamente com os funcionários, investindo e incentivando o futebol com o intuito de controlar, inclusive, o tempo de lazer dos operários. Conforme afirma Volpato (1984), durante algum tempo os funcionários se dividem-se entre a bola e sua função na mina, trabalhando no horário da manhã e treinando no horário da tarde ou vice e versa. Esta façanha acaba mudando a vida de muitos trabalhadores mineiros.

Figura 03 - Jogo do Esporte Clube Metropol no ano de 1962 no estádio Euvaldo Lodi 


\section{SABERES PEDAGÓGICOS}

Revista do Curso de Graduaçāo de Pedagogia - Unese

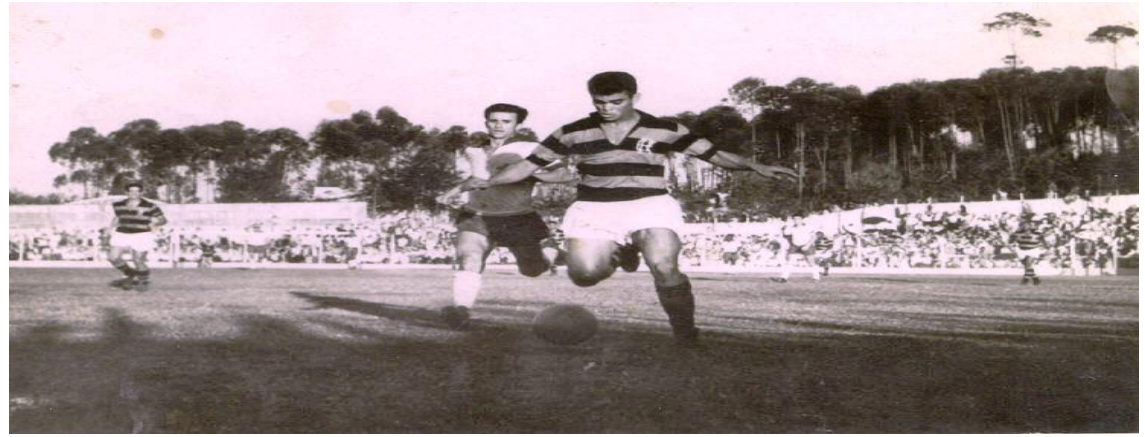

Fonte: Sede da Fundação Cultural de Criciúma.

O time Esporte Clube Metropol passa de time de vila operária, para time de renome internacional, conquistando muitas taças e títulos de campeão, aos poucos o time Metropol foi se popularizando e se tornando querido por moradores da região. Além de apaziguar os ânimos entre patrões e operários o time fez muitos trabalhadores saírem dos subterrâneos das minas para os campos de futebol

Segundo Carola (2002, p.159), para as mulheres das minas de Santa Catarina, o mineiro constituía-se num pretendente de prestígio social importante. Havia "uma propagação de discursos que procuravam destacar o trabalho como um dos trabalhos de melhor remuneração na região".

Em 1969, com o término da sociedade entre Diomício Freitas e Santos Guglielmi, chega ao final o estrelato do time Metropol, com isso o estádio Euvaldo Lodi que foi inaugurado em 1952, para ser sede oficial do time de futebol, deixa de ser sede de jogos oficiais, passando somente sediar treinos e jogos amadores da região. Nos anos de glória o estádio do Metropol foi palco de jogos e jogadores de sucesso. No ano de 1974, as terras onde se encontrava o Estádio de Futebol Euvaldo Lodi, terras estas que pertenciam à família dos donos da Carbonífera Metropolitana, foram desapropriadas e neste terreno houve a construção do Kartódromo Diomício Freitas este que foi cenário de poucas corridas. Como este foi um investimento que não deu muito certo, no ano de 1980 o Kartódromo foi desativado, voltando a ser um espaço reservado ao futebol, só que dessa vez futebol amador.

Figura 04 - Kartódromo Diomício Freitas, nos meados dos anos de 1970. 


\section{SABERES PEDAGÓGICOS}

Revista do Curso de Graduaçāo de Pedagogia - Unesc

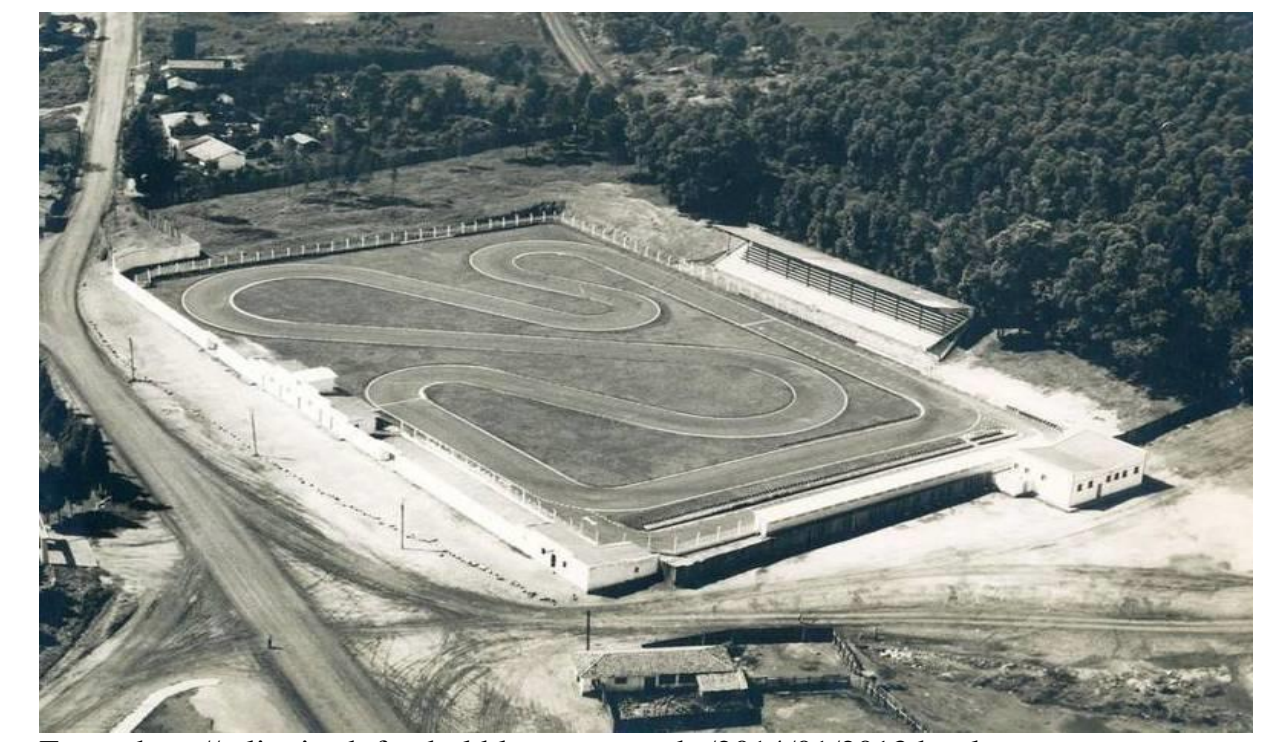

Fonte: http://reliquiasdofutebol.blogspot.com.br/2014/01/2013.html

Entre idas e vindas e em meio à pirita, ou seja, o rejeito do carvão, algo era certo, as crianças da Vila Operária tinham que estudar para serem mineiros e boas mães, mas o aprendizado não vinha somente da escola, este vinha principalmente das ruas e das experiências forjadas no dia-dia da Vila Operária.

\section{A VILA OPERÁria METROPOLITANA E A ESCOLA PARA OS FILHOS E FILHAS DOS MINEIROS: UMA ESCOLA DO CARVÃO}

Com o surgimento das companhias carboníferas não foram somente os homens que tiveram oportunidade de emprego nas minas de carvão, tanto as mulheres quanto as crianças também tiveram sua força de trabalho abarcada pelas minas de carvão. Era normal que a vida produtiva dos homens e das mulheres começasse bem cedo, muitas vezes antes mesmo da adolescência, este era um procedimento comum entre as famílias que faziam parte das vilas operárias. (CAROLA, 2002).

Cabe ressaltar que "o trabalho de homens e mulheres nas minas de carvão de Criciúma e região começava antes dos 14 anos de idade e, em muitos casos, antes dos 10" (CAROLA, 2002, p.45). As mulheres trabalharam como escolhedeiras de carvão, algumas tinham carteira assinada e outras trabalhavam por empreitadas, sendo assim quanto mais Saberes Pedagógicos, Criciúma, v. 1, nº1, janeiro/junho 2017.- Curso de Pedagogia- UNESC 
produziam mais recebiam, isso fazia com que muitas vezes levassem seus/suas filhos/as pequenos/as junto, algumas por não terem com quem deixá-los e outras simplesmente para aumentar suas rendas.

As crianças tinham participação ativa nas vilas onde moravam, pois era ali que passavam boa parte de sua vida, brincando, estudando, ajudando suas mães nos afazeres domésticos e assim que alcançavam certa idade já ingressavam na escolha do carvão ou trabalhavam como almoceiros. Segundo José Silva ${ }^{3}$, entrevistado por Giani Rabelo na elaboração de sua pesquisa para a tese de doutoramento:

\footnotetext{
Almoceiros eram os guris que levavam almoço para os pais na mina. A gente ia levar e tinham senhores que pagavam para a gente levar o almoço pra eles comer. Era a nossa profissão da época [...] Os guris faziam um arco de ferro, de alumínio não lembro mais o que era, e ali tinha umas aspas, pontas que eles penduravam 4, 5 panelas de uma vez pra conseguir levar mais almoço de uma vez. E tinha também quem levava carrinho de mão
}

Com a profissão de almoceiros muitas crianças contribuíram com o aumento da renda familiar e, ao mesmo tempo, foram se habituando ao oficio que era o mais valorizado na época, ou seja, trabalhar como mineiro.

Figura 05 - Almoceiros

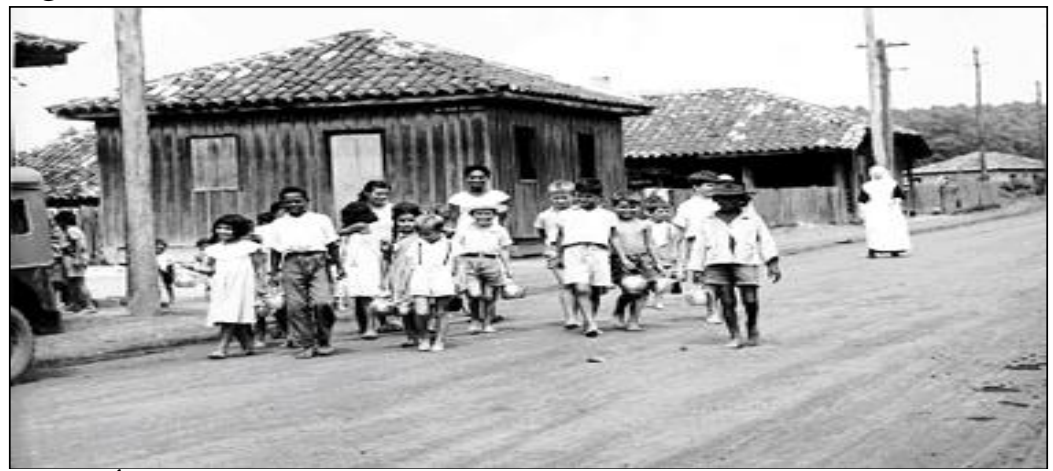

Fonte: Álbum/Relatório de Atividades das Pequenas Irmãs da Divina Providência (1955-1957)

\footnotetext{
${ }^{3}$ Entrevista concedida a Giani Rabelo em 29/10/2004, na cidade de Criciúma (SC).

Saberes Pedagógicos, Criciúma, v. 1, nº1, janeiro/junho 2017.- Curso de Pedagogia- UNESC
} 
Além desta tarefa, outras tarefas também contavam com o público infantil, mas ir a escola passou a ser um requisito para meninos e meninas,

A Escola Particular Filho do Mineiro, antiga denominação da EMEF Filho do Mineiro, teve sua emergência a partir das necessidades de uma vila operária que surge juntamente com a exploração do carvão no Bairro Metropol, Distrito de Rio Maina (SC).

Segundo o Histórico da EMEF Filho do Mineiro, a instituição era "particular", criada principalmente para atender os filhos e filhas dos mineiros que trabalhavam na Carbonífera Metropolitana. De acordo com o histórico da escola, a princípio a Escola Particular Filho do Mineiro foi mantida pela Carbonífera Metropolitana até meados do ano de 1977 e após um longo período de encerramento de suas atividades aconteceu sua reinauguração e passou a ser mantida pela Prefeitura Municipal de Criciúma. (HISTÓRICO DA ESCOLA, 2016, p 01).

Após tentativas frustradas em encontrar mais documentos sobre a trajetória inicial da EMEF Filho do Mineiro senti a necessidade de contar com as memórias de algumas pessoas que estudaram a época no estabelecimento escolar e que também fizeram parte da história do Bairro Metropolitana, ou "Metropol" como é denominado pelos atuais moradores. Partindo da reflexão de Meihy (2005, p.17), entendo que o uso da "História oral é uma alternativa para estudar a sociedade por meio de uma documentação feita com o uso de depoimentos gravados em aparelhos eletrônicos e transformados em textos escritos".

Os/as narradores/as que participaram desta pesquisa foram os/as ex-alunos/as Luiza Damasceno, Eliana Vilain e Roberto Luiz Vilain.

Luiza Damasceno nasceu no bairro Metropol no ano de 1963, seu pai ser foi operário da Carbonífera Metropolitana, Ela ingressou na Escola Particular Filho do Mineiro no ano de 1971, permanecendo até a $4^{\text {a }}$ série. Depois foi estudar na Escola Estadual Silva Alvarenga, na qual concluiu o $1^{\circ}$ Grau que ficava no mesmo bairro. Segundo ela, seu pai não permitiu que continuasse os estudos, por entender que era desnecessário e, além disso, perigoso para uma menina estudar no centro da cidade.

Eliana Vilain nasceu no ano de 1964, seu pai trabalhou na Carbonífera Metropolitana e ela estudou até o $4^{\circ}$ ano na escola Particular Filho do Mineiro. Depois foi para 
a Escola Estadual Eng. ${ }^{\circ}$ Sebastião Toledo dos Santos, na qual concluiu seus estudos. Mais tarde casou-se com Roberto Vilain, que à época era operário de uma mineradora.

O senhor Roberto Luiz Vilain, nasceu em 1963, também foi filho de mineiro e estudou na Escola Particular Filho Mineiro até a $4^{\mathrm{a}}$ série e depois foi para a SATC - Sociedade de Assistência aos Trabalhadores do Carvão. Nesta instituição não havia pagamento de mensalidade, o único requisito era que os mesmos não reprovassem, mas o senhor Roberto não conseguiu cumprir este requisito no fim do primeiro ano ali cursado ele foi "convidado" a se retirar da escola e no ano seguinte passou a estudar na EEEF Silva Alvarenga. Após concluir o $8^{\circ}$ ano, foi transferido para uma escola da rede estadual a fim de concluir o $2^{\circ}$ grau. Posteriormente, fez cursos que lhe deram qualificação e uma profissão que garantiu sua entrada e permanência no mercado de trabalho.

Segundo os entrevistados, a EMEF Filho do Mineiro foi criada em torno do ano de 1971, com a intenção de suprir as necessidades escolares dos filhos dos mineiros que trabalhavam na região do bairro Metropolitana. Os três comungam da ideia de que a Escola Particular Filho do Mineiro foi criada com o intuito oferecer educação para que os filhos dos funcionários da carbonífera pudessem estudar e ter uma profissão posteriormente. No entanto, a escola funcionava de $1^{\mathrm{a}}$ a $4^{\mathrm{a}}$ série, depois disso os meninos eram encaminhados automaticamente para a escola da SATC para receberem uma formação profissional e as meninas iam, em geral, para a Escola Estadual Silva Alvarenga. Esta funcionava até a $8^{\mathrm{a}}$ serei do $1^{\circ}$ Grau. Após concluírem o $1^{\circ} \mathrm{Grau}$, caberia aos pais decidirem se continuariam os estudos em outros estabelecimentos. De certa forma, essa realidade vai ao encontro do que Carola (2002, p. 221) expõe:

No processo de formação das famílias mineiras, os homens assumiam para si a exclusividade dos serviços tidos como perigosos e altamente desgastantes fisicamente - trabalhos valorizados pela sociedade. As mulheres cabiam os cuidados de casa, dos filhos, o preparo dos alimentos e uma serie de trabalhos ainda mais desvalorizados.

Sobre o local aonde funcionou a Escola Particular Filho do Mineiro, Luiza e Eliana relata que ao ser criado para atender os alunos do $1^{\circ}$ ao $4^{\circ}$ ano, foram utilizadas as antigas instalações do hotel Metropol, este que servia de alojamento para os funcionários que vinham 
de outras localidades para trabalhar na mineradora e permaneciam no local até conseguirem acomodações definitivas.

Ao referir-se à arquitetura da escola Luiza conta que ela era de material com as repartições e o assoalho de madeira, possuía 4 salas de aula, 2 banheiros, secretaria e cozinha. Já Eliana afirma que era uma escola "bem boa de estudar", pois possuía leis rigorosas e os alunos tinham muitas obrigações a cumprir, era exigido respeito por parte dos alunos para com os professores. Ela recorda- que era exigido de todos o uso do uniforme, as meninas usavam saias bordos plissadas, com camisa branca e gravata vermelha, meias brancas e tênis enquanto que os meninos usavam calça de tergal bordô, gravata e camisa branca.

O senhor Roberto, além de concordar com Luiza e Eliana acrescenta que as salas eram bem limpas, as mesas das salas eram compridas e de tábua e que vários alunos sentavamse juntos. Ele lembra que a escola dispunha de uma área bem grande e tinha um campo de futebol, construído no pátio ao lado pelo coordenador do estabelecimento, para que os meninos pudessem jogar.

Importante ressaltar que cada entrevistado lembra e destaca os detalhes da escola de acordo com aquilo que mais significou enquanto crianças, mas relatado a partir do presente. Para Meihy (2005, p.77) "Em estado de oralidade, a memória é sempre dinâmica e mutável, sujeito ás vicissitudes das circunstâncias. Sempre mudamos nossa forma de recordar e montamos esquemas narrativos dependentes de fatores externos a nós mesmos".

Sobre o corpo docente que fez parte da Escola Particular Filho do Mineiro nos meados da década de 1970, os entrevistados buscam em suas memórias recordações que marcaram suas vidas na breve trajetória que tiveram na escola e lembra-se de algumas professoras, como: Salete Passeto que foi a primeira professora de Elaine e Luiza no $1^{\circ}$ ano e Vilma Milanese que foi professora de Roberto Vilain. Lembram também do seu Anselmo, conhecido pelos alunos como Sargento Anselmo pela rigorosidade que tratava os alunos ao coordenar o estabelecimento.

Outras lembranças são trazidas à tona sobre a experiência escolar. Luiza lembra que ela era boa aluna, comportada, que nunca foi castigada durante período que frequentou a escola, pois na sua avaliação respeitava e cumpria com as regras estabelecidas a ela e seus colegas. 


\section{SABERES PEDAGÓGICOS}

Revista do Curso de Graduaçāo de Pedagogia - Unesc

Eliana lembra-se que na escola era servida uma merenda bem gostosa em canecas e que a merendeira era muito carinhosa.

Eliana e Luiza participavam do balé da escola, desfilavam no Sete de Setembro e lembram, inclusive, que os alunos da escola faziam apresentações no Centro Recreativo dos Trabalhadores da Carbonífera Metropolitana, hoje Ginásio do Metropol.

Figura: 06 Centro Recreativo dos Trabalhadores da Carbonífera Metropolitana

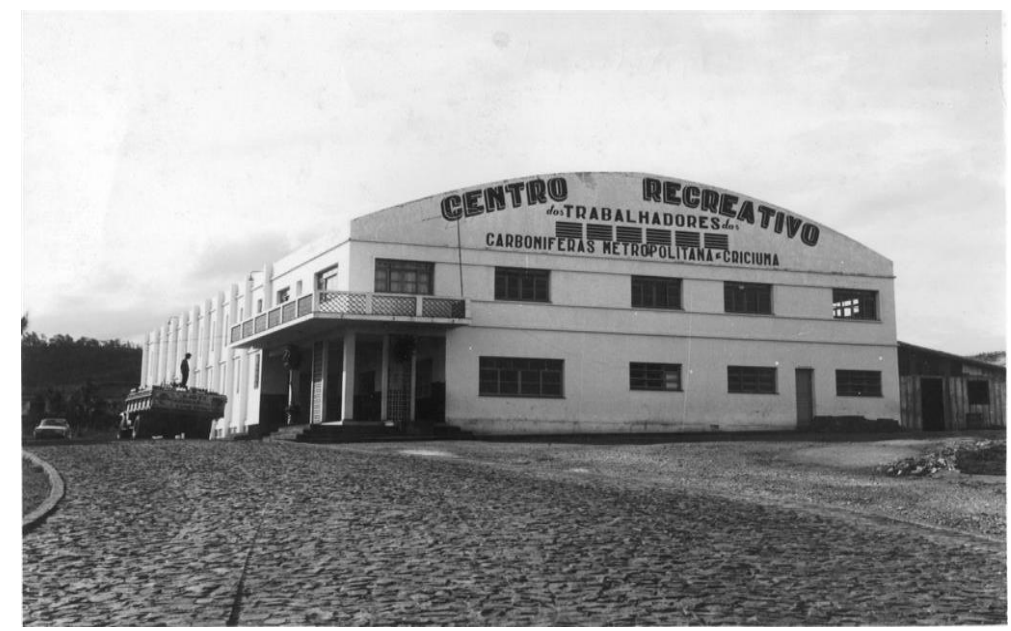

Fonte: Arquivo histórico da Fundação Cultural de Criciúma

Roberto em suas memórias reporta-se ao time de futebol que tinham formado na escola, às bagunças que ele fazia junto com seus colegas, lembra-se também que nas datas de aniversário era de praxe que o aniversariante levasse um lanche especial a fim de partilhar com os colegas de sala. Ao lembrar-se disso ele sorri e conta que geralmente quem levava os tão esperados lanches eram as meninas.

Nas lembranças dos entrevistados a Escola Particular Filho do Mineiro envolvia seus alunos em várias atividades católicas e nas datas especiais eles eram levados pelos professores para se apresentarem na igreja do bairro. Dentre as apresentações que eles mais realizavam eram as apresentações do Dia das Mães, na ocasião a imagem da Nossa Senhora era coroada.

Figura: 07 Apresentação do Dia das Mães na Igreja do Metropol realizada pelos alunos da Escola Particular Filho do Mineiro.

Saberes Pedagógicos, Criciúma, v. 1, nº1, janeiro/junho 2017.- Curso de Pedagogia- UNESC 


\section{SABERES PEDAGÓGICOS}

Revista do Curso de Graduaçāo de Pedagogia - Unese

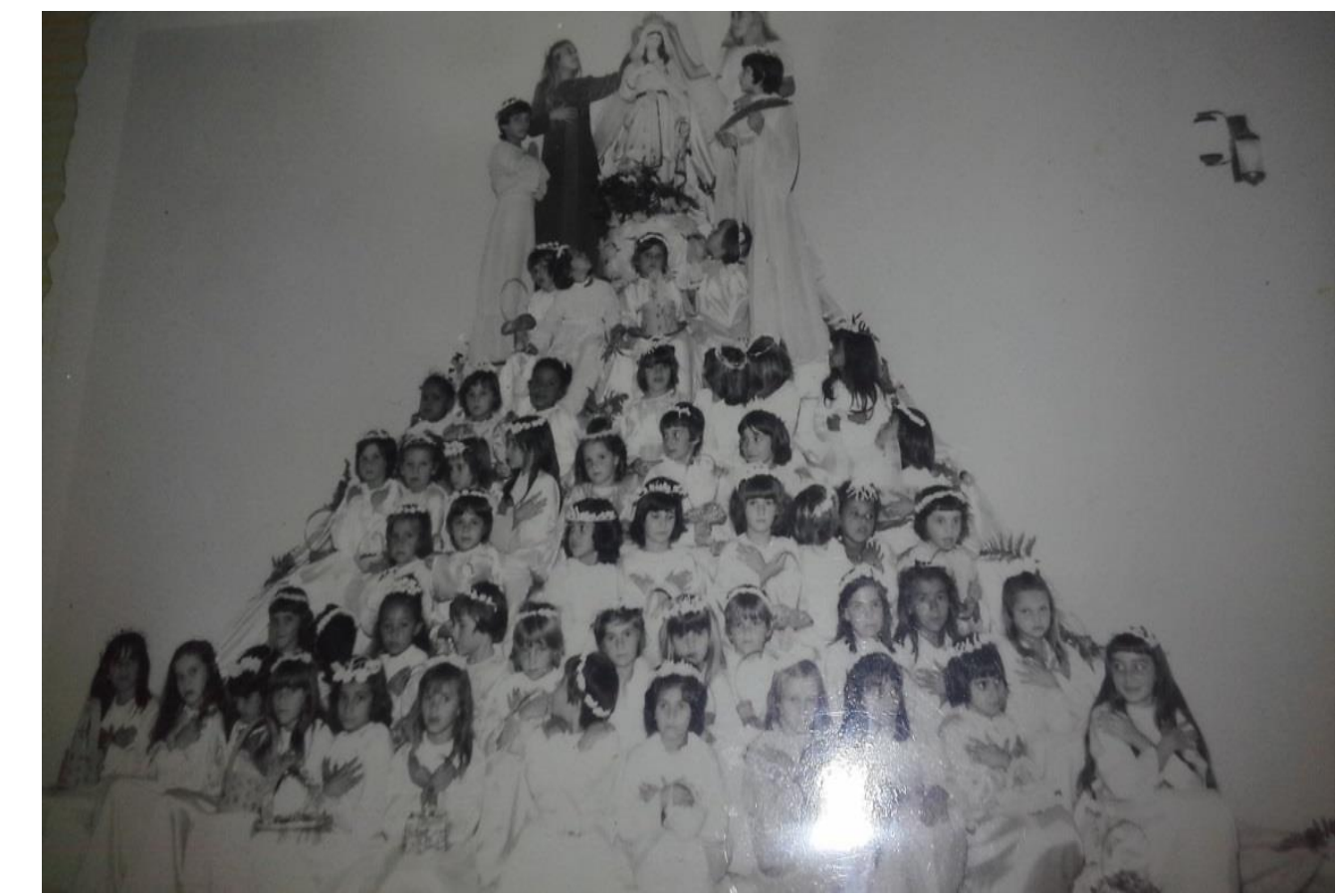

Fonte: Arquivo Particular de Eliana Vilain

Quando perguntados sobre a importância do Bairro Metropol para suas vidas várias manifestações surgiram.

A senhora Luiza Damasceno aponta que o Bairro Metropol foi importante em sua vida, pois foi nele que ela se criou, estudou, casou, criou seus filhos viu o bairro crescer, acompanhou a transformação das ruas que eram de pirita e barro e hoje são ruas de asfalto, com sinalização, viu as casas pretas de carvão se tornarem casas das mais variadas cores e modelos.

Já para Eliana o bairro Metropol faz parte de sua vida pelo fato de ela ter nascido ali, além disso, foi ali que ela estudou, casou e mora até hoje na casa que seu pai adquiriu quando era funcionário da carbonífera Metropolitana. Foi neste bairro que ela conheceu Roberto, seu esposo, com quem estudou na mesma escola durante a infância, com quem divide a casa que foi de seus pais. Já para Roberto o bairro foi e é importante para sua vida, pois ele acompanhou toda a transformação do bairro, que na sua infância era escuro, com estradas formadas por morros de pirita, casas enfileiradas, com poucas árvores e sem iluminação pública.

Das recordações que marcaram a infância dos entrevistados surgem os brinquedos que recebiam no dia do Natal da Carbonífera Metropolitana, dos desfiles do dia 07 de setembro, 
das brincadeiras de rua, de seus ex-colegas que estudaram na mesma época na Escola Particular Filho do Mineiro.

Entre tantas lembranças boas da infância, da vida no bairro surge uma que destoa, foi quando a carbonífera fechou uma de suas "bocas de mina" no bairro e deixou de enviar recursos para manter a escola, ficando abandonada a partir de 1977 e não recebeu mais alunos novos, ficando fechada por, aproximadamente 10 anos. O prédio onde funcionava o educandário foi utilizado como moradia para famílias que não tinham casas.

De acordo com a legislação oficial, Decreto $N^{\circ}$ SE/130/86, o prefeito municipal de Criciúma, José Augusto Hulse, criou pela Lei 2.222 de 16/07/87 a Escola Reunida Valeli Ana Cambruzzi dos Santos, no mesmo bairro. Tudo indica, que realmente ao ser fechada a Escola Particular Filho do Mineiro levou algum tempo para ter outro estabelecimento no local. O que leva a este entendimento, é que esta denominação sofre mudança. Depois de um ano a mesma recebe nova denominação, passando a chamar-se Escola Reunida ${ }^{4}$ Filho do Mineiro, sob a justificativa que o nome da escola foi escolhido a partir de consulta à comunidade escolar.

De acordo como histórico escolar, no ano de 1988 a escola que é mantida pela Prefeitura Municipal de Criciúma funcionava em um prédio cedido pelo empresário Realdo Guglielmi (dono da Carbonífera Metropolitana) e atendia aproximadamente 86 alunos tendo 08 funcionários entre professores e serventes (HISTÓRICO DA ESCOLA, 2016 p.10).

No ano de 1994, é alterada novamente a nomenclatura da escola e esta passa a ser chamada de Escola Básica Filho do Mineiro, pois nesse ano ela passa atender alunos da $5^{\mathrm{a}}$ a $8^{\mathrm{a}}$ série.

Com o Decreto Municipal nº 604 de 22/12 de 2003, as escolas municipais passam por uma retificação em seus nomes e com isso a escola passa a se chamar Escola Municipal de Ensino Infantil e Ensino Fundamental Filho do Mineiro, atendendo 500 alunos entre educação infantil ao $9^{\circ}$ ano. À época havia 58 colaboradores entre funcionários e estagiários.

No ano de 2010, a escola é ampliada, mas em fevereiro de 2013 a escola é atingida por um temporal e o teto desaba, fazendo com que aproximadamente 600 alunos passem a ter aulas no Ginásio de Esportes Metropol, próximo à escola. Foi somente no início do ano letivo

\footnotetext{
${ }^{4}$ As Escolas Reunidas tinham até 4 turmas e ofertavam as 4 primeiras séries do Fundamental do Ensino Primário. Saberes Pedagógicos, Criciúma, v. 1, nº1, janeiro/junho 2017.- Curso de Pedagogia- UNESC
} 
de 2014, após a escola ter passado por reformas e reconstrução de suas partes atingidas que os alunos voltaram a estudar no prédio da escola.

No ano de 2015 a escola por uma reforma estrutural e deixa de oferecer a Educação Infantil, passando a atender somente alunos do $1^{\circ}$ ano ao $9^{\circ}$ ano do Ensino Fundamental.

A EMEF Filho do Mineiro atualmente em 2016, possui 505 alunos, sendo 250 alunos nos anos iniciais do $1^{\circ}$ ao $5^{\circ}$ ano e 205 alunos do $6^{\circ}$ ao $9^{\circ}$ ano. Desde a inauguração da escola até o ano de 2015 a escola atendia alunos da educação infantil e da pré-escola, hoje estes alunos foram recolocados em outras escolas do bairro.

Nos dias atuais a escola ocupa $1272 \mathrm{~m}^{2}$ de construção que é composto por 03 blocos, possui 11 salas de aula, 15 banheiros sendo 02 banheiros para portadores de deficiência motora, biblioteca, sala de informática, sala adaptada para laboratório de ciências, cozinha, rampas de acesso para cadeirantes. A escola possui aproximadamente 80 funcionários entre equipe diretiva, professor, equipe de apoio e estagiários, conta com Grêmio Estudantil, Associação de Pais e Professores e com a comunidade. Abaixo segue a Equipe Diretiva atual da escola.

Imagem 08 Equipe Diretiva da EMEF Filho do Mineiro (2016) 

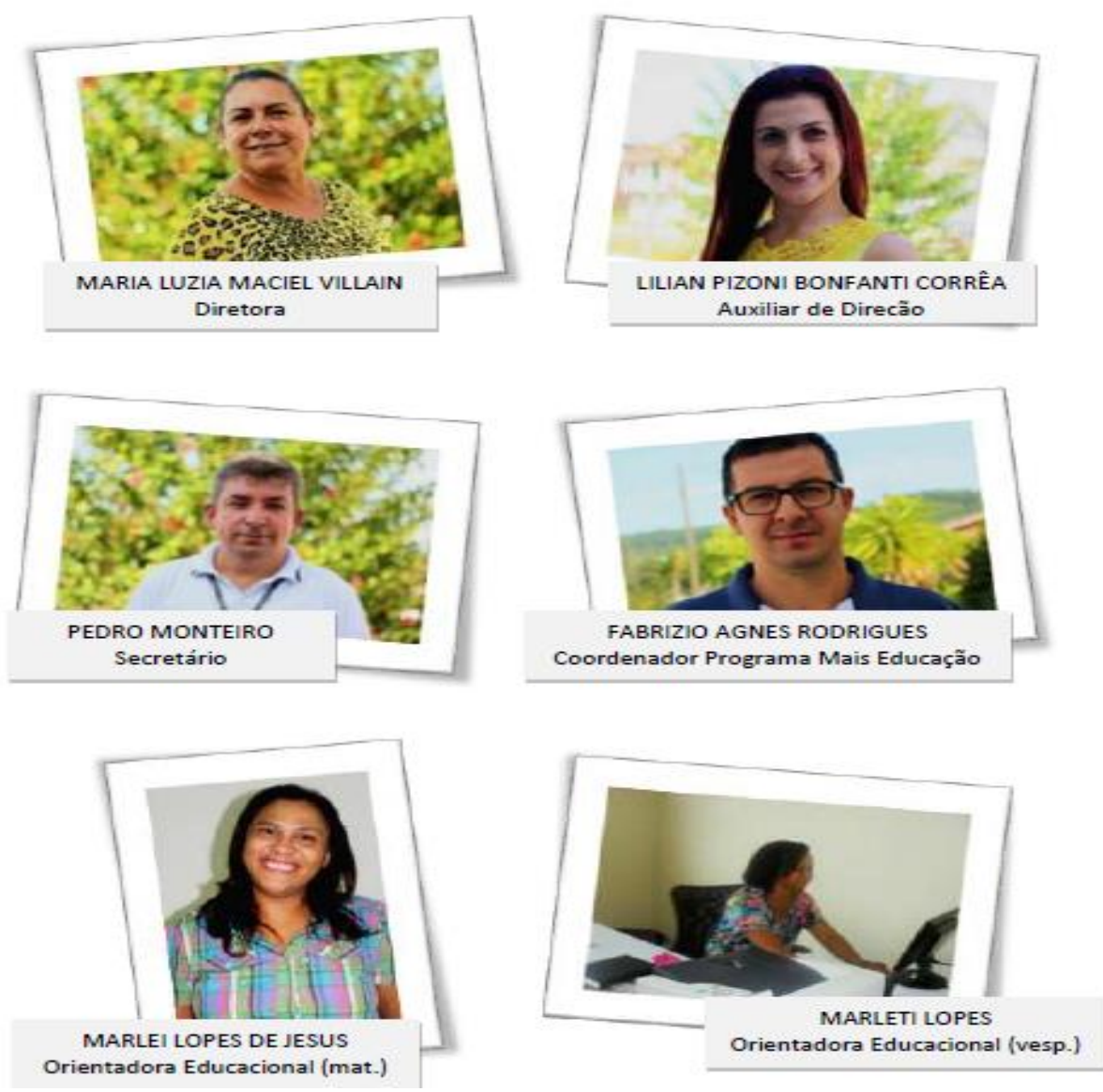

Fonte: Arquivo da EMEF Filho do Mineiro.

\section{CONCLUSÃO}

A presente pesquisa foi a oportunidade que tive de levar ao conhecimento dos leitores deste trabalho a história e trajetória de um estabelecimento escolar que despontou há mais de 04 décadas. Para que esta pesquisa ganhasse vida, foi imprescindível a contribuição de algumas pessoas que tiveram participação assídua nesta trajetória.

Durante as entrevistas, foi possível ver a emoção das pessoas quando falavam de suas experiências quando crianças, das expectativas que estas tinham em relação à vida adulta, das recordações evocadas aos falarem sobre a escola, de colegas e professores que tomaram outros rumos. Também, pude perceber a felicidade que elas sentiram em apontar pessoas que 
cresceram e envelheceram ali no mesmo lugar que elas, entre estas há algumas que são vizinhas a mais de 50 anos.

A partir desta pesquisa pude compreender a importância da história oral e das memórias para os sujeitos, pois é através destas que é possível, relembrar e reconstruir acontecimentos que muitas vezes ficam escondidos no baú das lembranças.

Um dos momentos mais agradáveis da pesquisa foi o momento das coletas de dados, pois foi onde eu pude ouvir e ver pessoas falando de sua infância como se estivessem voltados no tempo e estivessem lá ainda.

Ao realizar este estudo creio ter contribuído para dar visibilidade a parte da história da EMEF Filho do Mineiro, no entanto, algumas questões ficam em aberto e a principal delas é porque ela inicia com este nome, depois muda para Valeli Ana Cambruzzi dos Santos e mais tarde volta a se chamar Filho do Mineiro. Há vestígios de que isso tenha ocorrido por pressão da comunidade, no entanto, para entender esta questão há necessidade de mais aprofundamento.

Os objetivos propostos nesta pesquisa foram alcançados com base nos poucos documentos encontrados e nas memórias dos entrevistados. Contudo, é lamentável saber que muitos documentos e registros fundamentais para a história desta instituição de ensino tenham se perdido ao longo do tempo. De qualquer forma, acredito que esta pesquisa contribuirá para a preservação de parte deste patrimônio educativo que foi e é tão importante para as famílias que moraram no bairro Metropol e que ainda moram.

\section{REFERÊNCIAS:}

AMANDO, Vanessa. Parte do forro de uma escola desabou nesta sexta-feira, em Criciúma. Engeplus Telecom. 22 fev 2013. Disponível em http://www.engeplus.com.br/noticia/educacao/2013/parte-do-forro-de-uma-escola-desabounesta-sexta-feira-em-criciuma/.Acesso em 16 set 2016.

BELOLI, Mário. et al. A história do Carvão em Santa Catarina: a história do Carvão em Santa Catarina. Criciúma: Imprensa Social de Santa Catarina, 2002. 300 p.

CAROLA, Carlos Renato. Dos subterrâneos da história: as trabalhadoras das minas de carvão de Santa Catarina. Florianópolis: UFSC, 2002. 262 p. 
FILHO, Alcides Goularti; MORAES, Fabio Farias. Formação, expansão e desmonte parcial do complexo carbonífero catarinense. Revista História \& Perspectivas. Uberlândia. Editora da UFSC, jan. jun. v. 1. n. 40. 2009. Disponível em:

http://www.seer.ufu.br/index.php/historiaperspectivas/article/view/19214/10351.

Acesso em: 25 de junho de 2016.

Carbonífera Metropolitana S/A. Disponível

em:http://www.carboniferametropolitana.com.br/empresa/historico.Acesso 16 ago 2016.

HISTÓRICO, Arquivo. FCC Turismo. Criciúma. Disponível em:

http://www.criciuma.sc.gov.br/site/turismo/arquivo_historico?title=metropol\&epoca=\&fonte= $\underline{\text { \&cor}=\& \text { categoria }}=$ Acesso 16 ago 2016.

MEIHY, José Carlos Sebe Bom. Manual da história oral. 5. ed. São Paulo: Loyola, 2005. $296 \mathrm{p}$.

PINHEIRO, José Maurício dos Santos. Da iniciação científica ao TCC: uma abordagem para os cursos de tecnologia.In: Pesquisa Cientifica. Rio Janeiro: Editora Ciência Moderna, LTDA,2010.

SANTOS, Milena dos. Escola municipal filho do mineiro volta às mãos da comunidade escolar. AMREC: Criciúma. Disponível em:

http://www.amrec.com.br/noticias/index/ver/codMapaItem/42508/codNoticia/224643.Acesso 16 ago 2016.

TEIXEIRA, Tati. Projeto No PL 38/2011. Câmera Municipal: poder legislativo de Criciúma. Disponível: http://www.camaracriciuma.sc.gov.br/documento/projeto-no-pl-38-2011-21026. Acesso 16 ago 2016.

VOLPATO, Terezinha Gascho. A Pirita Humana: os mineiros de Criciúma. Florianópolis: Ed.UFSC/ Assembléia Legislativa do Estado de Santa Catarina, 1984. 262p.

CARBONÍFERA METROPOLITANA. Histórico. Disponível em

http://www.carboniferametropolitana.com.br/empresa/historicoem: Acesso em: 16 de ago. 2016

http://www.minerios.com.br/EdicoesInt/326/9/A_colonizadora_que_transformouse_em_carbo nifera.aspx

https://www.lume.ufrgs.br/bitstream/handle/10183/12864/000630915.pdf?sequence $=$

Entrevista concedida a Giani Rabelo, no dia 05/04/2006, em Criciúma/SC

Fontes Orais:

Saberes Pedagógicos, Criciúma, v. 1, n ${ }^{\circ}$, janeiro/junho 2017.- Curso de Pedagogia- UNESC 
Eliana Villain. Ex-aluna da Escola Particular Filho do Mineiro. Nascido em 08/01/1964, na cidade de Criciúma/SC Entrevista concedida a Bibiana Trindade de Freitas, em 05/10/2016 na cidade de

Criciúma/SC

Luiza Colombo Damasceno, Ex-aluna da Escola Particular Filho do Mineiro. Nascido em 06/12/1964 na cidade de Criciúma/SC Entrevista concedida a Bibiana Trindade de Freitas, em 05/10/2016 na cidade de Criciúma/SC.

Roberto Luiz Villain. Ex-aluno da Escola Particular Filho do Mineiro. Nascido em 14/08/1963, na cidade de Criciúma/SC Entrevista concedida a Bibiana Trindade de Freitas, em 05/10/2016 na cidade de Criciúma/SC. 